УДК 159.923

DOI 10.23951/2307-6127-2020-2-197-203

\title{
ПСИХОЛОГИЧЕСКИЕ КОМПОНЕНТЫ ИННОВАЦИОННОГО ПОВЕДЕНИЯ КАК НЕОБХОДИМЫЕ СОСТАВЛЯЮЩИЕ В ПРОФЕССИОНАЛЬНОЙ ПОДГОТОВКЕ СТУДЕНТОВ
}

\author{
Н. А. Буравлева
}

Томский государственный педагогический университет, Томск

\begin{abstract}
Необходимость модернизации общества актуализирует вопросы инновационного поведения личности, развития ее инновационного потенциала. Исследование инновационного поведения человека основывается на деятельностном подходе в психологии. В настоящее время перспективной моделью при подготовке специалистов является модель профессионального саморазвития, где акцент сделан на внутренней активности человека, потребности в самореализации. Необходимым условием для развития инновационного потенциала студентов вузов является образовательная среда, рассматриваемая как социальное пространство, посредством которого человек включается в культурные связи общества. Образовательная среда должна создавать единый и целостный процесс инновационной подготовки специалистов.
\end{abstract}

Ключевые слова: инновачионный потенциал, инновачионное поведение, саморазвитие личности, образовательная среда.

Сегодня, решая вопросы модернизации многих сфер жизни, общество стоит перед необходимостью построения научно обоснованной системы взглядов, принципов и приоритетов по формированию и развитию инновационной активности человека. В различных документах, касающихся усовершенствования экономики страны, отмечается, что ключевая роль в этом процессе отводится молодым людям, которым предстоит осуществлять планы прорывных изменений. Цель государственной молодежной политики на данный момент определена как создание условий для успешной социализации и эффективной самореализации молодежи, использование ее потенциала в интересах инновационных преобразований [1].

Как отмечают многие исследователи, помимо нанотехнологий в вопросе кардинальных изменений в стране важно отношение людей к их необходимости, так как инновационная экономика невозможна без формирования инновационного поведения граждан [2].

Новые вызовы времени меняют образовательные запросы общества, требуют более высокого качества профессиональной подготовки будущих специалистов, чья компетентность и творческая активность будут существенно влиять на уровень развития страны. Это предполагает инвестиции в высшее профессиональное образование, призванное подготовить специалистов, востребованных инновационной экономикой. Недостаточная оценка этой проблемы становится фактором, сдерживающим общественное развитие.

В этой ситуации актуализируются вопросы изучения специфики инновационного поведения личности, развития инновационного потенциала обучающихся в условиях профессионального образования. Значимость их исследования связана с несколькими социальными аспектами: ориентированностью на эффективную деятельность будущих специалистов, получением продуктов высокого качества, новых технологий.

Изучение инновационного поведения личности основывается на деятельностном подходе в психологии, который отражен в исследованиях А. Н. Леонтьева, Е. А. Климова, 
В. Д. Шадрикова, С. Л. Рубинштейна. Согласно данному подходу, личность формируется и развивается в деятельности, которая выступает в качестве особой формы активности человека, его взаимодействия с миром [3]. В ней человек не только обнаруживается, но и созидается, определяется. В деятельности личность проявляется двояко. С одной стороны, происходит развитие субъекта в деятельности, с другой - формируются различные способы ее реализации, разрешения противоречий, возникающих в процессе деятельности, которые осуществляются в вариантах самоорганизации, саморегуляции, самосовершенствовании [4, с. 105].

По мнению И. В. Атамановой, С. А. Богомаза, инновационная деятельность как раз и создает благоприятные предпосылки для развития личности, ее самораскрытия, самореализации, эффективного использования внутреннего потенциала и совершенствования. Именно в инновационной деятельности человек открывает и формирует среду свободного движения, в которой совершает выход «за пределы» сложившихся образа жизни, опыта, требований, норм, стереотипов, устоявшихся приспособительных поведенческих форм. Как утверждают исследователи, в инновационном поведении человек реализует свою «актуальную потенциальность», способность к трансцендированию, а личностный рост становится актуальным состоянием, позволяющим развиваться и достигать все более высоких целей [5].

На сегодняшний день существует несколько определений, что такое инновационное поведение. Так, например, отмечается, что это инициативный тип индивидуального или коллективного поведения, связанный с систематическим освоением социальными субъектами новых способов деятельности в различных сферах общественной жизни, созданием новых объектов материальной и духовной культур. Инновационное поведение выступает важным способом развития человека, группы, сообщества [6].

Во многих определениях подчеркивается, что инновационное поведение обусловлено инновационным потенциалом, предрасположенностью специалиста к такого рода поведению, наличием ряда характеристик, прежде всего творческих способностей, открытости опыту, новым идеям, дивергентности мышления, которые помогают совершенствовать профессиональную деятельность, а также наличием социокультурных средств. Благодаря инновационному поведению личность не приспосабливается, а максимально развивается [7].

В. Е. Клочко, Э. В. Галажинский отмечают, что инновационное поведение возникает в точках жизненного пространства людей, где сходятся такие факторы, как возможности человека, среда, отвечающая этим возможностям, готовность личности реализовать свои возможности. Они подчеркивают, что согласно принципу современной теории самоорганизации, открытые системы, к которым можно отнести и человека, существуют в ходе своего усложнения и за счет этого усложнения. Когда процесс усложнения останавливается, начинается процесс ее распада, разрушения, система прекращает свое существование. Инновационное поведение отличается тем, что благодаря ему личность не приспосабливается, а максимально развивается [8, с. 146].

Инновационное поведение определяется своеобразием личности, всем предыдущим опытом деятельности человека, особенностями его воспитания и развития, поэтому для исследования его предрасположенности к инновационному поведению необходимо учитывать различные составляющие личности. В исследованиях отмечается, что для осуществления инновационного поведения необходим рефлексивный компонент - уровень осознания человеком самого себя как субъекта своего образа жизни. Следует отметить также, что принципиально значимы ценностно-смысловая сфера личности, ее мировоззрение, толерантность к неопределенности, потребность в самореализации. Кроме этого необходимы такие виды компетенций, как коммуникативная, проектная, информационная [7]. 
Инновационное поведение рассматривается исследователями как комплексный феномен. Характеризуя инновационное поведение, они выделяют творческий потенциал, креативность личности. Именно в инновационном поведении человек реализует внутренне присущее ему творческое начало. В сегодняшней ситуации, когда постоянно происходят изменения, перед человеком ставятся новые задачи, меняется образ жизни, и инновационное поведение открывает человеку пространство свободного движения, помогает реализовать свои возможности в действительности.

Так как отличительной особенностью инновационного поведения является ориентированность на создание новых продуктов, технологий, можно утверждать, что инновативность - это своего рода практическое применение творческих идей. Вместе с тем многие ученые отмечают, что инновационное поведение помимо генерации идей отличается тем, что оно нацелено на их реализацию и внедрение. Кроме этого инновационное поведение подразумевает достижение максимальных результатов в работе, увеличение эффективности и продуктивности в деятельности [7].

Проявление инновационного поведения человеком коррелирует с его социально-психологическими конструктами. Среди них можно отметить положительное отношение к инновациям, способность к разумному риску, готовность отстаивать свою точку зрения, так как продвижение новых идей часто связано с преодолением препятствий, защитных механизмов сотрудников, работающих в рамках традиционной системы, устоявшихся взглядов и действий.

Наибольший интерес сегодня представляет проблема инициации инновационного поведения. Для современной педагогики и психологии в настоящее время становится актуальной задача формирования и развития личности, ориентированной на инновационное поведение. При близости понятий «формирование» и «развитие» в данном вопросе всетаки более значим процесс развития, так как он предполагает субъектность, активность человека, где в большей степени проявляется саморазвитие личности, ее становление. В процессе формирования акцент переводится на внешние воздействия и усилия [8].

В настоящее время при подготовке специалистов наиболее перспективной признается модель профессионального саморазвития. Главными в данной модели являются внутренняя активность человека, потребность в самореализации, самопроектировании и самостроительстве. Важная составляющая образовательного процесса - развитие личности обучающегося, так как именно личностные характеристики определяют уровень и характер деятельности. Значимость периода обучения в вузе определяется тем, что именно в студенческом возрасте происходят изменения в мировоззрении молодых людей, выбор между ценностями консерватизма и открытости к изменениям, ценностями трансцендентности и гедонизма.

Для подготовки современных специалистов к профессиональной деятельности очень важно развивать у них инновационный потенциал. Анализируя понятие «инновационный потенциал», Т. Ю. Артюхова, А. В. Голов подчеркивают, что понятие «потенциал» неразрывно связано с категориями «возможность» и «действительность». При реализации возможности она переходит в категорию действительности», появляется новая «возможность», т. е. наблюдается взаимопереход данных категорий, который носит название «актуализация потенции». Раскрытие потенциала многие ученые связывают с личностным развитием, стремлением человека быть тем, кем он может стать [9].

С одной стороны, понятие «инновационный потенциал личности» характеризует динамическое свойство личности как субъекта и инициатора практической новаторской деятельности, а с другой - способность принимать нововведения и адаптироваться к ним как 
объекту инновационной системы. То есть в этом понятии отражаются генерализованное свойство человека осуществлять преобразовательный способ взаимодействия с миром, а также способность осмысленно и дифференцированно воспринимать инновации и адаптироваться к нововведениям.

Потенциал личности обучающихся представляет собой ее ресурсный фонд, который может быть актуализирован и задействован для достижения определенного результата при благоприятных условиях развития способностей личности, а также меру возможностей личности в сфере постановки и разрешения задач ее деятельности. Необходимым условием для этого процесса является образовательная среда, рассматриваемая как социальное пространство, посредством которого человек включается в культурные связи общества. Эта среда должна отличаться отсутствием строгой регламентации деятельности и мышления, а также наличием определенной свободы действий. С точки зрения культурно-исторической концепции Л. С. Выготского, образовательная среда создает зону ближайшего развития для личности, условия для ее совершенствования [10].

В настоящее время подготовка специалиста связана с непрерывностью и открытостью образования, где идет постоянный процесс развития личности в изменяющемся мире. Процесс развития инновационного потенциала личности во многом определяется через «личное присутствие» человека в своем образовании, возможность выбирать путь собственного личностного и профессионального становления, когда актуализируется интеллектуальный и психологический потенциал человека. Саморазвитие детерминирует развитие его способности к самоуправлению и взаимосвязь конструктов профессионально-образовательного пространства, что является основой проектирования профессионального будущего специалиста [11]. При этом происходит переход потенциальных возможностей в свою актуальную форму. Это в полной мере соответствует субъектно-деятельностному и культурноисторическому подходам в науке [8, с. 212].

Как подчеркивают В. Е. Клочко, Э. В. Галажинский, инновационное поведение личности отличается сверхадаптивным, сверхнормативным характером. Особенность человека заключается в том, что он способен выходить за пределы обстоятельств, предписаний, себя самого. Будущее общества в большой степени зависит от развития у людей стремления к самосовершенствованию и использованию своих навыков и талантов, поэтому при изучении вопросов инновационного поведения следует рассматривать человека как самоактуализирующуюся, саморазвивающуюся, самореализующуюся личность [8].

При подготовке молодых людей к профессиональной деятельности существует объективная потребность учитывать тот факт, что современные специалисты должны быть готовы к решению мультидисциплинарных проблем, широкого круга инновационных задач, выходящих за рамки традиционных представлений и ранее сложившейся системы обучения. Современная реальность диктует необходимость подготовки человека к профессиональной деятельности в условиях перемен, подразумевает наличие у него универсальных знаний, умений, навыков, компетенций, умение совмещать в себе функции проектировщика, аналитика-эксперта, квалифицированного управленца. Кроме этого при подготовке специалиста необходимо принимать во внимание, что он должен быть психологически готов к самостоятельному освоению новых сфер деятельности, уметь целенаправленно создавать ранее неизвестное информационное содержание [12].

Для решения поставленных задач необходима реализация моделей и механизмов подготовки специалистов в высших учебных заведениях, так как основной целевой группой, призванной обеспечить в ближайшем будущем инновационный прорыв и модернизацию экономики страны, являются обучающиеся в вузах студенты. В процессе активизации ин- 
новационного потенциала молодых людей важно создавать развивающую инновационную научно-образовательную среду в университетах, направленную на формирование опыта участия в разработке, внедрение инноваций, реализацию идей, расширение возможности коммерциализации перспективных студенческих научно-исследовательских замыслов. Существенно также наличие в этой деятельности полного инновационного цикла: от генерации научной идеи до ее внедрения. С точки зрения развития инновационного потенциала, большую ценность имеет участие студентов в осуществлении проектов технопарков, бизнес-инкубаторов, различных научных структур университетов и научно-исследовательских институтов. Творческой реализации молодых людей во многом способствует их участие в конкурсах, выставках, конференциях, школах-семинарах.

Учитывая современные требования общества при подготовке специалиста, в образовательных программах необходимо отражать вопросы формирования инновационной культуры обучающихся. Такое развитие возможно, если университеты в своей деятельности опираются на серьезную научную и технологическую базу, собственный научно-методический потенциал. Будучи фундаментальным условием подготовки специалистов, инновационный ресурс университетов должен отвечать запросам социума, новым укладам постиндустриального типа.

Немаловажную роль в развитии инновационного потенциала молодежи играет наличие в высшем учебном заведении преподавателей, ориентированных на научное творчество, имеющих опыт реализации инновационных проектов, уделяющих в своих учебных курсах внимание новаторским идеям. Современный преподаватель сам должен активно участвовать в исследовательской деятельности, транслировать положительное отношение к новшествам, уважительно относиться к предложениям обучающихся, помогать им в самореализации. Отличительной особенностью современного преподавателя вуза является то, что при взаимодействии с молодыми людьми ему необходимо найти способы обращения к их личному опыту, вывести их на самостоятельное овладение знаниями.

Требования, предъявляемые сегодня к высшим учебным заведениям, обусловливают отказ от известных шаблонов, стереотипов, заставляют пересмотреть устоявшиеся стандарты. Вызовы времени ставят перед необходимостью менять многое в парадигме высшего образования, осуществлять научный и профессиональный поиск в определении подготовки специалистов, развитии их инновационного потенциала.

\section{Список литературы}

1. Луков В. А., Луков С. А., Погорский Э. К. Инновационный потенциал новых поколений и молодежная политика на современном этапе развития общества // PolitBook. 2014. № 2. C. 6-18.

2. Пегин Н. А. Ценностноориентированная личность как условие успешной модернизации // Вестник Тихоокеанского государственного университета. 2010. № 4. С. 239-244.

3. Леонтьев А. Н. Деятельность. Сознание. Личность. М.: Смысл, 2005. 352 с.

4. Рубинштейн С. Л. Принцип творческой самодеятельности (к философским основам современной педагогики) // Вопросы психологии. 1986. № 4. С. 101-109.

5. Атаманова И. В., Богомаз С. А. Инновативность современной молодежи и культурные факторы социальноэкономического развития // Социальная и экономическая психология. Ч. 1: Состояние и перспективы исследований. М.: Ин-т психологии РАН, 2018. С. 281-289.

6. Социология: Энциклопедия. URL: https://sociology_encyclopedy.academic.ru (дата обращения: 30.01.2020).

7. Ваулина Т. А. Современные подходы к определению понятия «инновационное поведение» // Вестник Томского государственного университета. 2010. № 340. С. 168-171.

8. К Клочко В. Е., Галажинский Э. В. Психология инновационного поведения. Томск: Том. гос. ун-т, 2009.240 с.

9. Артюхова Т. Ю., Голов А. В. Личностный потенциал в контексте философско-психологического знания // Человек в изменяющемся мире. Красноярск: Сибирский федеральный университет, 2014. С. 66-71. 
10. Выготский Л. С. Психология. М.: ЭКСМО-Пресс, 2000. 1008 с.

11. Зеер Э. Ф., Мешкова И. В. Детерминация саморазвития личности в профессионально-образовательном пространстве // Образование и наука. 2012. № 9 (98). С. 78-89.

12. Голдырева В. А. Взаимосвязь культурных ценностей и отношения к инновациям // Вестник Томского гос. пед. ун-та (TSPU Bulletin). 2013. Вып. 12 (140). С. 62-67.

Буравлева Наталья Анатольевна, кандидат психологических наук, доцент, Томский государственный педагогический университет (ул. Киевская, 60, Томск, Россия, 634061). E-mail: buravleva@tspu.edu.ru

Материал поступил в редакиџю 04.02.2020.

DOI 10.23951/2307-6127-2020-2-197-203

\section{PSYCHOLOGICAL COMPONENTS OF INNOVATIVE BEHAVIOR AS NECESSARY PARTS IN PROFESSIONAL TRAINING OF STUDENTS}

\section{N. A. Buravleva}

\section{Tomsk State Pedagogical University, Tomsk, Russian Federation}

The modernization of society raises issues of training personnel with developed innovative potential. In this situation, the issues of studying the specifics of the innovative behavior of the individual, the development of the innovative potential of students in the context of professional education are relevant. The study of innovative potential and innovative human behavior is based on an activity-based approach in psychology. Innovative activity creates favorable conditions for the development of personality, the effective use of internal potential. In innovative behavior, a person realizes his "actual potentiality", the ability to transcendence, and personal growth becomes an actual state. For the development of the innovative potential of the individual, it is fundamentally important to develop the worldview of the individual, tolerance to uncertainty, and the need for self-realization. The problem of initiating innovative behavior is of great interest today. For modern pedagogy and psychology, the task of forming and developing a personality focused on innovative behavior is currently becoming urgent. Although the concepts of "formation" and "development" are close, the development process is still more significant in this issue, since it involves subjectivity, human activity. Currently, a promising model in the preparation of a modern specialist is a model of professional selfdevelopment, where the emphasis is on the internal activity of a person, the need for selfrealization. A necessary condition for the development of innovative potential is the educational environment, where a person is included in the cultural ties of society. The educational environment should contribute to the formation of an innovative culture of students, create a single and holistic process of innovative training of specialists.

Keywords: innovative potential, innovative behavior, personal self-development, educational environment.

\section{References}

1. Lukov V. A., Lukov S. A., Pogorskiy E. K. Innovatsionnyy potentsial novykh pokoleniy i molodezhnaya politika na sovremennom etape razvitiya obshchestva [The innovative potential of new generations and youth policy at the present stage of development of society]. PolitBook, 2014, no. 2, pp. 6-18 (in Russian).

2. Pegin N. A. Tsennostnooriyentirovannaya lichnost' kak usloviye uspeshnoy modernizatsii [Value-oriented personality as a condition for successful modernization]. Vestnik Tikhookeanskogo gosudarstvennogo universiteta - Bulletin of PNU, 2010, no. 4, pp. 239-244 (in Russian). 
3. Leont'ev A.N. Deyatel'nost'. Soznaniye. Lichnost' [Activity. Consciousness. Personality]. Moscow, Smysl Publ., 2005. 352 p. (in Russian).

4. Rubinshteyn S. L. Printsip tvorcheskoy samodeyatel'nosti (k filosofskim osnovam sovremennoy pedagogiki) [The principle of creative initiative (to the philosophical foundations of modern pedagogy)]. Voprosy psikhologii - Voprosy Psychologii, 1986, no. 4, pp. 101-109 (in Russian).

5. Atamanova I. V., Bogomaz S. A. Innovativnost' sovremennoy molodezhi i kul'turnye faktory sotsial'no-ekonomicheskogo razvitiya [Innovation of modern youth and cultural factors of socio-economic development]. Sotsial'naya i ekonomicheskaya psikhologiya. Chast' 1: Sostoyaniye i perspektivy issledovaniy [Social and Economic Psychology. Part 1: State and prospects of research]. Moscow, Psychology Institute RAS Publ., 2018, pp. 281-289 (in Russian).

6. Sotsiologiya: Entsiklopediya [Sociology: Encyclopedia] (in Russian). URL: https://sociology_encyclopedy.academic.ru (accessed 30 January 2020).

7. Vaulina T. A. Sovremennye podkhody k opredeleniyu ponyatiya "innovatsionnoye povedeniye" [Modern approaches to the definition of the concept of "innovative behavior"]. Vestnik Tomskogo gosudarstvennogo universiteta - Tomsk State University Journal, 2010, no. 340, pp. 168-171 (in Russian).

8. Klochko V. E., Galazhinskiy E. V. Psikhologiya innovatsionnogo povedeniya [Psychology of innovative behavior]. Tomsk, TSU Publ., 2009. 240 p. (in Russian).

9. Artyukhova T. Yu., Golov A. V. Lichnostnyy potentsial v kontekste filosofsko-psikhologicheskogo znaniya [Personal potential in the context of philosophical and psychological knowledge]. Krasnoyarsk, Siberian Federal University Publ., 2014. Pp. 66-71 (in Russian).

10. Vygotskiy L. S. Psikhologiya [Psychology]. Moscow, EKSMO-Press Publ., 2000. 1008 p. (in Russian).

11. Zeyer E. F., Meshkova I. V. Determinatsiya samorazvitiya lichnosti v professional'no-obrazovatel'nom prostranstve [Determination of personal self-development in the professional and educational space]. Obrazovaniye i nau$k a-$ Education and Science, 2012, vol. 98, no. 9, pp. 78-89 (in Russian).

12. Goldyreva V. A. Vzaimosvyaz' kul'turnykh tsennostey i otnosheniya k innovatsiyam [The relationship of cultural values and attitudes towards innovation]. Vestnik Tomskogo gosudarstvennogo pedagogicheskogo universiteta TSPU Bulletin, 2013, vol. 140, no 12, pp. 62-67 (in Russian).

Buravleva N. A., Tomsk State Pedagogical University (ul. Kiyevskaya, 60, Tomsk, Russian Federation, 634061).E-mail: buravleva@tspu.edu.ru 